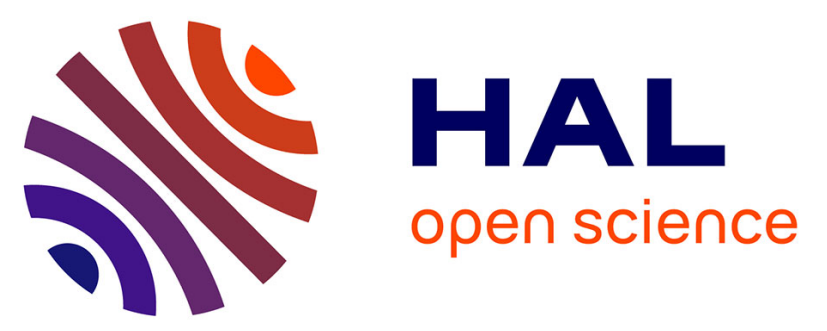

\title{
Synthesis by a Cost-Effective Method and Electroluminescence of a Novel Efficient Yellowish-Green Thermally Activated Delayed Fluorescent Molecule
} Ikbal Marghad, Dae Hyeon Kim, Xiaohui Tian, Fabrice Mathevet, Corinne Gosmini, Jean-Charles Ribierre, Chihaya Adachi

\section{To cite this version:}

Ikbal Marghad, Dae Hyeon Kim, Xiaohui Tian, Fabrice Mathevet, Corinne Gosmini, et al.. Synthesis by a Cost-Effective Method and Electroluminescence of a Novel Efficient Yellowish-Green Thermally Activated Delayed Fluorescent Molecule. ACS Omega, 2018, 3 (2), pp.2254-2260. 10.1021/acsomega.7b01570 . hal-01718124

\section{HAL Id: hal-01718124 \\ https://hal.sorbonne-universite.fr/hal-01718124}

Submitted on 27 Feb 2018

HAL is a multi-disciplinary open access archive for the deposit and dissemination of scientific research documents, whether they are published or not. The documents may come from teaching and research institutions in France or abroad, or from public or private research centers.
L'archive ouverte pluridisciplinaire HAL, est destinée au dépôt et à la diffusion de documents scientifiques de niveau recherche, publiés ou non, émanant des établissements d'enseignement et de recherche français ou étrangers, des laboratoires publics ou privés.

\section{(c) (1) $\$$}

Distributed under a Creative Commons Attribution - NonCommerciall 4.0 International 


\title{
Synthesis by a Cost-Effective Method and Electroluminescence of a Novel Efficient Yellowish-Green Thermally Activated Delayed Fluorescent Molecule
}

\author{
Ikbal Marghad, ${ }^{\dagger, \ddagger}$ Dae Hyeon Kim, ${ }^{\dagger}$ Xiaohui Tian, ${ }^{\S}$ Fabrice Mathevet, ${ }^{\|}$Corinne Gosmini, \\ Jean-Charles Ribierre, ${ }^{* \dagger, \perp}$ and Chihaya Adachi ${ }^{*},+\perp \odot$ \\ ${ }^{\dagger}$ Center for Organic Photonics and Electronics Research (OPERA), Kyushu University, Motooka 744, Nishi, Fukuoka 819-0395, \\ Japan \\ ${ }^{\ddagger}$ Laboratoire de chimie moléculaire LCM Ecole Polytechnique, CNRS, 91128 Palaiseau Cedex, France \\ ${ }^{\S}$ Department of Polymer Science and Engineering, Zhejiang University, Hangzhou 310027, China \\ "Sorbonne Universités, UPMC Univ Paris 06, CNRS, Institut Parisien de Chimie Moléculaire (IPCM), Chimie des Polymères, 75005 \\ Paris, France \\ ${ }^{\perp}$ Adachi Molecular Exciton Engineering Project, Japan Science and Technology Agency (JST), ERATO, Fukuoka 819-0395, Japan
}

Supporting Information

ABSTRACT: A new thermally activated delayed fluorescent molecule, TRZ 3(Ph-PTZ), containing three phenothiazines as donor units and a 2,4,6-triphenyl-1,3,5-triazine as the acceptor unit was synthesized using a simple cost-effective method based on a cobalt catalyzed cross-coupling. This compound was tested in organic light-emitting diodes and was found to show superior yellowish-green electroluminescence performance with a maximum external quantum efficiency of $17.4 \%$ and a maximum luminance value of $7430 \mathrm{~cd} / \mathrm{m}^{2}$.
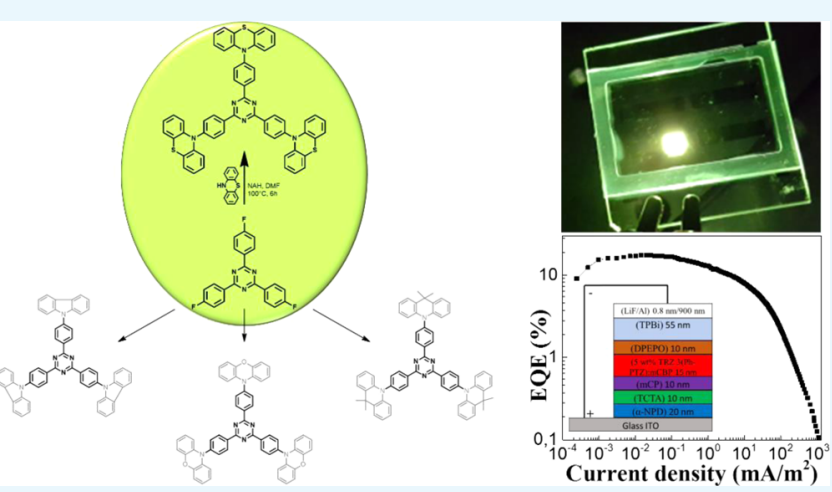

\section{INTRODUCTION}

Since the demonstration of the first generation of organic lightemitting diodes (OLEDs) based on conventional fluorescent emitters in 1987 by Tang and VanSlyke, ${ }^{1}$ the development of new organic electroluminescent materials as well as OLED device physics and engineering has been the subject of intensive studies. In particular, since the pioneering works of Thompson and Forrest, the development of phosphorescent OLEDs based on organometallic emitters has been proven to be very successful. ${ }^{2}$ These heavy-metal complexes, which exhibit efficient luminescence from the triplet states at room temperature, have been already used in a range of OLEDs exhibiting internal quantum efficiencies of $100 \%$. Recently, by improving the light outcoupling of the devices with a partial horizontal orientation of the light-emitting dipoles, it was shown that the maximum external quantum efficiency (EQE) of phosphorescent OLEDs can be higher than 35\%. ${ }^{3}$ Nevertheless, the high cost of heavy metals such as iridium, which are needed to improve the spin-orbital interaction and achieve highly efficient radiative transition from the triplet excited state to the ground state, is a major problem for their use in commercial applications. An alternative toward highly efficient electroluminescent devices was proposed a few years back, which is based on the use of thermally activated delayed fluorescent (TADF) emitters. ${ }^{4}$ The working principle of this third OLED generation is based on the upconversion of the lowest triplet excited state $\left(\mathrm{T}_{1}\right)$ to the lowest singlet excited state $\left(S_{1}\right)$, using thermal energy. For efficient TADF emission, a very small energy gap $\left(\Delta E_{\mathrm{ST}}\right)$ between $S_{1}$ and $\mathrm{T}_{1}$ and a high yield of triplet-to-upconverted-singlet formation are both required.

A large number of efficient TADF materials have been synthesized during the last few years, showing the importance of the molecular design of the emitters to simultaneously achieve large radiative decay rate and small $\Delta E_{\mathrm{ST}} \cdot{ }^{5-9}$ This molecular design is generally based on a combination of electron donor and acceptor units, which minimizes the spatial overlap between the lowest unoccupied molecular orbital (LUMO) and the highest occupied molecular orbital (HOMO). In terms of efficiency, a variety of TADF OLEDs has already shown performances equivalent to those achieved in phosphorescent devices. For instance, a green TADF molecule

Received: December 5, 2017

Accepted: January 2, 2018

Published: February 26, 2018 
with $100 \%$ photoluminescence quantum yield (PLQY) and $100 \%$ upconversion of the triplet to the singlet excited state was recently used in devices with a maximum EQE of $41.5 \%{ }^{10}$ Hirata et al. demonstrated blue TADF OLEDs with 100\% internal quantum efficiency and a maximum EQE of $20.6 \%{ }^{11}$ Regarding red TADF OLEDs, Zhang et al. reported on the realization of high-performance electroluminescent devices with a maximum EQE of $8.1 \%$ for an emission maximum at 624 nm. ${ }^{12}$ Such a panel of blue, green, and red (RGB) colors is evidently crucial for different fields of application, such as solidstate lighting and display technologies. In parallel, efficient yellow electroluminescence is also of strong interest because a convenient way to obtain white light emission is to use blue and yellow emitters. In that context, high-performance yellow TADF OLEDs have been already reported with a maximum external quantum efficiency as high as $18.4 \%{ }^{13}$ Nevertheless, the design and synthesis of new yellow TADF emitters are still crucial for the development of display and white lighting applications. In addition, further reducing the cost of synthesis of TADF emitters by developing simple and convenient synthetic routes, which do not require the use of expensive catalysts and can be carried out in ambient atmosphere, is also extremely relevant to this research field.

\section{RESULTS AND DISCUSSION}

In this study, we designed, synthesized, and analyzed the electroluminescence properties of a novel, highly efficient, yellowish-green TADF emitter, TRZ 3(Ph-PTZ), containing the 2,4,6-triphenyl-1,3,5-triazine for the central acceptor moiety and peripheral phenothiazine donor units (employed in a wide range of applications). ${ }^{14-26}$ The chemical structure of this molecule is displayed in Figure 1. The design of this molecular

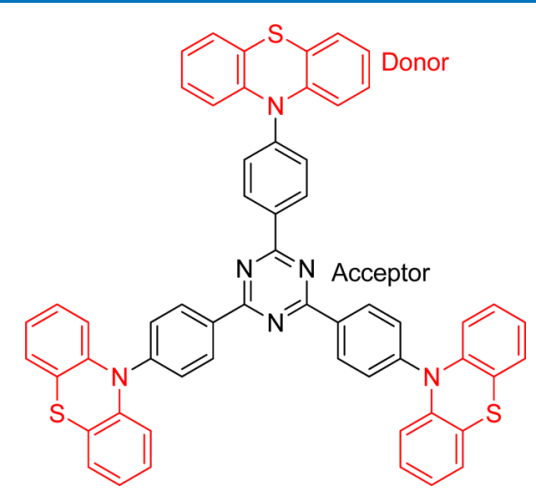

Figure 1. Molecular structure of TRZ 3(Ph-PTZ).

structure was motivated by a previous report where a 2,4,6tri((phenoxazinyl)phenyl)-1,3,5-triazine TADF emitter was used in a yellowish-orange OLED with a maximum EQE of about $13 \%$. $^{27}$

To synthesize this compound, a simple and convenient method is proposed, which is based on the cobalt catalyzed cross-coupling of arylzinc with aryl halide. The added value of this synthetic method is to lower the production cost, thanks to the low-cost reagents employed for the synthesis, leading then to the reduction of cost of OLED. This advantage fits evidently well with the asset of the third OLED generation based on metal-free emitters.

Most of the classical reactions used for the synthesis of OLED molecules based on 1,3,5-triazine are dominated by the use of expensive metal catalysts such as palladium. ${ }^{10,27-30}$
To avoid the use of such expensive catalysts in the final coupling of the donor part (2,4,6-triphenyl-1,3,5-triazine) with the acceptor one (phenothiazine) in the TRZ 3(Ph-PTZ) molecule, we synthesized a fluorine phenyl-triazine intermediate building block based on a catalyzed cross-coupling reaction between an arylzinc and an aryl halide (Scheme 1). The arylzinc derivative 1 ((4-fluorophenyl)zinc bromide) was first prepared from 4-bromofluorobenzene in the presence of inexpensive reagents such as a cobalt salt and zinc dust in acetonitrile solvent. The resulting organozinc 1 was then engaged in the coupling reaction with the commercially available 2,4,6-trichloro-1,3,5-triazine at room temperature to form the key intermediate building block 2 (2,4,6-tris (4fluorophenyl)-1,3,5-triazine). ${ }^{31-39}$ To the best of our knowledge, this latter coupling reaction is the first example of one-pot cobalt catalyzed cross-coupling of 3 equiv of 4-(fluorophenyl) zinc bromide with 2,4,6-trichloro-1,3,5-triazine. Finally, the coupling last step of phenothiazine on fluorinated triazine $\mathbf{2}$ was carried out using the synthetic method reported previously for pyrrole and fluorobenzene derivatives to lead to the TRZ 3(PhPTZ) TADF molecule. ${ }^{40,41}$ Chemical characterization of TRZ 3(Ph-PTZ), including NMR and HRMS, is provided in Supporting Information.

To gain insights into the electronic states of TRZ $\mathbf{3}(\mathbf{P h}$ PTZ), we performed density functional theory (DFT) and time-dependent density functional theory (TDDFT) calculations. The ground-state geometries were optimized with Gaussian09 software at the B3LYP/6-31G* level. Phenothiazine has been described in previous studies to be a nonplanar, central six-membered ring because of the presence of sulfur. In such a moiety, the length of the $(\mathrm{C}-\mathrm{S})$ and $(\mathrm{C}-\mathrm{N})$ bonds was estimated to be $1.76-1.77$ and $1.44-1.45 \AA$, respectively. ${ }^{29}$ The longer length of the $(\mathrm{C}-\mathrm{S})$ bond leads to two different molecular conformations because of rotational dynamics of the phenothiazine. $^{29,42,43}$ In that context, the TRZ 3(Ph-PTZ) molecule, which bears three phenothiazine units, is expected to show different conformations. DFT calculations reveal two equatorial (E-1, E-2) and two axial (A-1, A-2) conformers that show only minor energy differences (see Figure 2 and Tables S1 and S2). Energy difference between E-1 and E-2 (and that between A-1 and A-2) is negligible; thus, we will focus only on the first equatorial and the first axial conformers in the following paragraphs for simplicity. Figure 3 shows the HOMOs and LUMOs of the equatorial-TRZ 3(Ph-PTZ) and axial-TRZ 3(Ph-PTZ) obtained. It can be seen that both E-1 and A-1 have degenerate frontier molecular orbitals (Table S3). Such degeneracy is the result of the symmetrical properties of both conformers, implying that all these orbitals can participate in the transition process. In E-1, the HOMOs are mainly distributed on the phenothiazine unit, whereas the LUMOs are localized on the triazine and phenyl units. Only small overlaps between the HOMOs and LUMOs are present at the phenyl ring connecting phenothiazine and triazine units. In the case of A-1, however, the overlaps are quite large.

As shown in Table S4, TDDFT results reveal that $S_{0} \rightarrow S_{1}$ of E-1 is mainly the transitions between its HOMO and LUMO (70.4\%). For A-1, HOMO - 1, HOMO - 2, LUMO, and LUMO + 1 played equally important roles in its $S_{0} \rightarrow S_{1}$. It can also be seen that the $S_{0} \rightarrow T_{1}$ transitions for both conformers follow similar trends. According to the orbital distributions showed in Figure 3, one can expect that E-1 should have smaller $\Delta E_{\mathrm{ST}}$ than that of A-1 because $\Delta E_{\mathrm{ST}}$ is proportional to the overlap between involved orbitals. This deduction is 
Scheme 1. Synthesis of the TADF Molecule TRZ 3(Ph-PTZ) Based on Key Intermediate Building Block 2 (2,4,6-Tris(4fluorophenyl)-1,3,5-triazine)

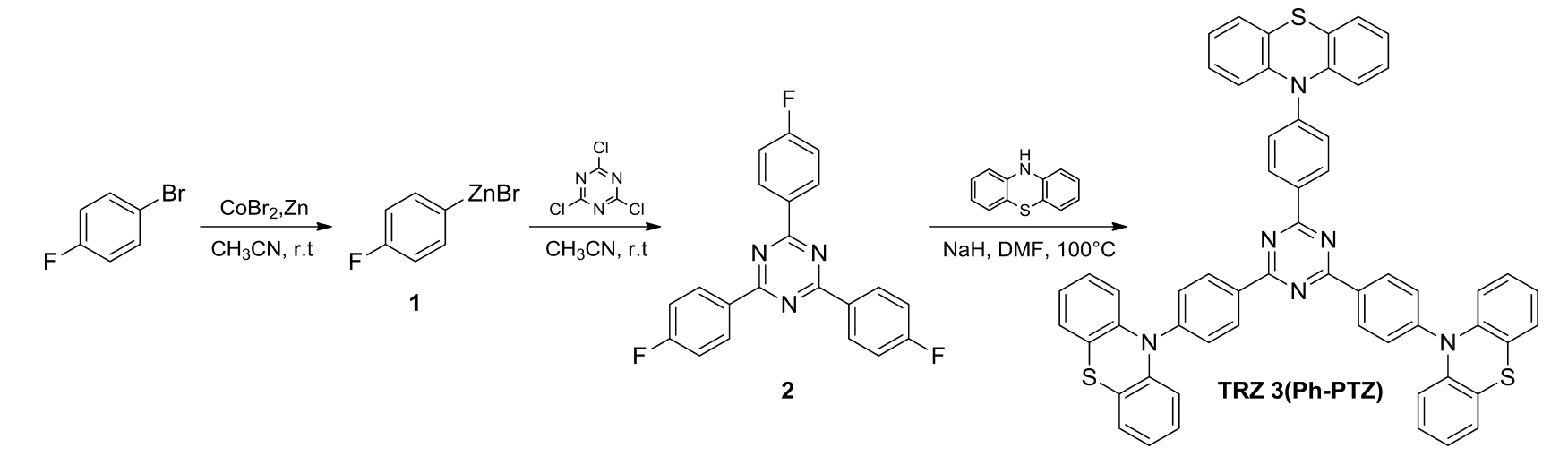

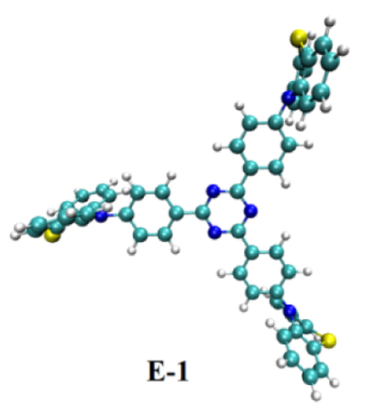

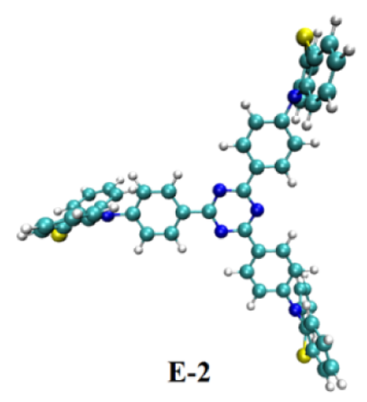

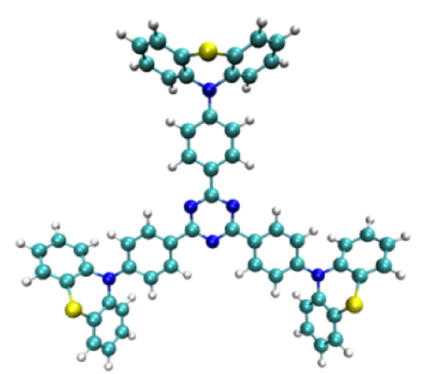

A-1

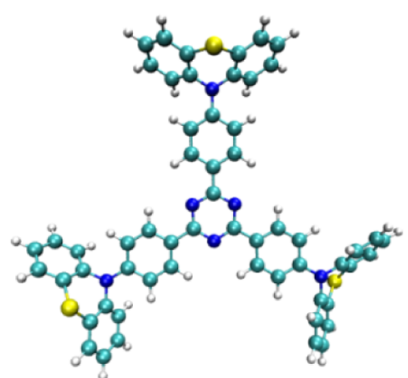

A-2
Figure 2. Geometrical structures of the four conformers. Optimized at B3LYP/6-31G* level of theory.

confirmed by our TDDFT results using the optimized $S_{0}$ structures: the calculated $\Delta E_{\mathrm{ST}}$ of $\mathrm{E}-1$ is only $0.0079 \mathrm{eV}$, whereas $\Delta E_{\mathrm{ST}}$ of A-1 is $0.71 \mathrm{eV}$. Apparently, thermally driven upconversion from $T_{1}$ to $S_{1}$ in E-1 could be quite effective.

The UV-visible absorption and steady-state photoluminescence (PL) spectra of TRZ 3(Ph-PTZ) at room temperature in toluene solution with a concentration of $1 \times 10^{-5} \mathrm{M}$ are presented in Figure 4a. It should be mentioned that a detailed investigation of the photophysical properties of a TADF emitter containing a phenothiazine electron donor and 2,4,6-triphenyl1,3,5-triazine electron acceptor unit has been already reported. ${ }^{29}$ In particular, the different conformers of this molecule and their photophysical properties were clearly identified. On the basis of the results published in this previous report, the absorption and PL spectra of TRZ 3(Ph-PTZ) can be easily understood. The absorption spectrum of TRZ 3(PhPTZ) shows an intense absorption below $300 \mathrm{~nm}$, which can be assigned to the $1\left(\pi, \pi^{*}\right) \leftarrow S_{0}$ transition derived from the triazine acceptor unit. The weak absorption tail between 400 and $500 \mathrm{~nm}$ and the broad and structureless absorption peak centered at $366 \mathrm{~nm}$ are both related to the intramolecular charge transfer (ICT) character of this molecule. In particular, the absorption tail at longer wavelengths is due to the $1 \mathrm{CT}-\mathrm{S}_{0}$ transition of the equatorial conformer. As expected, the PL spectrum obtained with an excitation wavelength of $340 \mathrm{~nm}$ shows a dual emission with peaks around 431 and $575 \mathrm{~nm}$. Similar to what was observed in a previous study, ${ }^{29}$ the peak at $575 \mathrm{~nm}$ shows the highest intensity with a large Stokes shift and a full width at half-maximum of $108 \mathrm{~nm}$. This ICT emission can be straightforwardly assigned to the excited state of the quasiequatorial conformation (E-1) of TRZ 3(Ph-PTZ). The peak centered at about $431 \mathrm{~nm}$ exhibits a much lower intensity with a small Stokes shift, and this emission is attributed to the excited state of the quasi-axial conformer (A-1). It should be emphasized that this quasi-axial conformer shows an overlap between HOMO and LUMO on the triazine acceptor unit. The observation of a smaller Stokes shift for this conformer can be explained by the effect of the $\pi-\pi^{*}$ character deduced from the non-negligible HOMO-LUMO overlap. ${ }^{29}$

To determine whether the dual emission from TRZ 3(PhPTZ) can also be observed in the solid state, an organic thin film based on a blend containing $2 \mathrm{wt} \%$ of TRZ 3(Ph-PTZ) in a 3,3'-bis ( $N$-carbazolyl)-1,1'-biphenyl (mCBP) host was prepared by thermal evaporation onto a fused silica substrate. The mCBP host was selected because of the high triplet $T_{1}$ energy of this material, which prevents back energy transfer from the guest to the host molecules and confines the triplets within the guest emitters. The absorption and steady-state PL spectra of this sample are displayed in Figure $4 \mathrm{~b}$. Owing to the small concentration of the guest molecules in the host, the absorption spectrum is completely dominated by the absorption from mCBP. More importantly, the PL spectrum obtained with an excitation wavelength of $340 \mathrm{~nm}$ does not show any emission from the mCBP matrix, indicating that an efficient energy transfer takes place from the host to TRZ 3(Ph-PTZ) molecules. In addition, similarly to what was observed in toluene solution, the photoluminescence from the doped film exhibits a dual emission with two peaks at about 427 and $520 \mathrm{~nm}$. Noticeably, whereas the blue emission peak from the quasi-axial conformer presents nearly the same maximum wavelength in solution and thin film, the PL spectrum from the equatorial conformer in the solid state shows a significant blue shift of around $55 \mathrm{~nm}$. Because TADF materials showing ICT generally exhibit a strong solvatochromism effect, a plausible explanation for this observation could be related to the different 

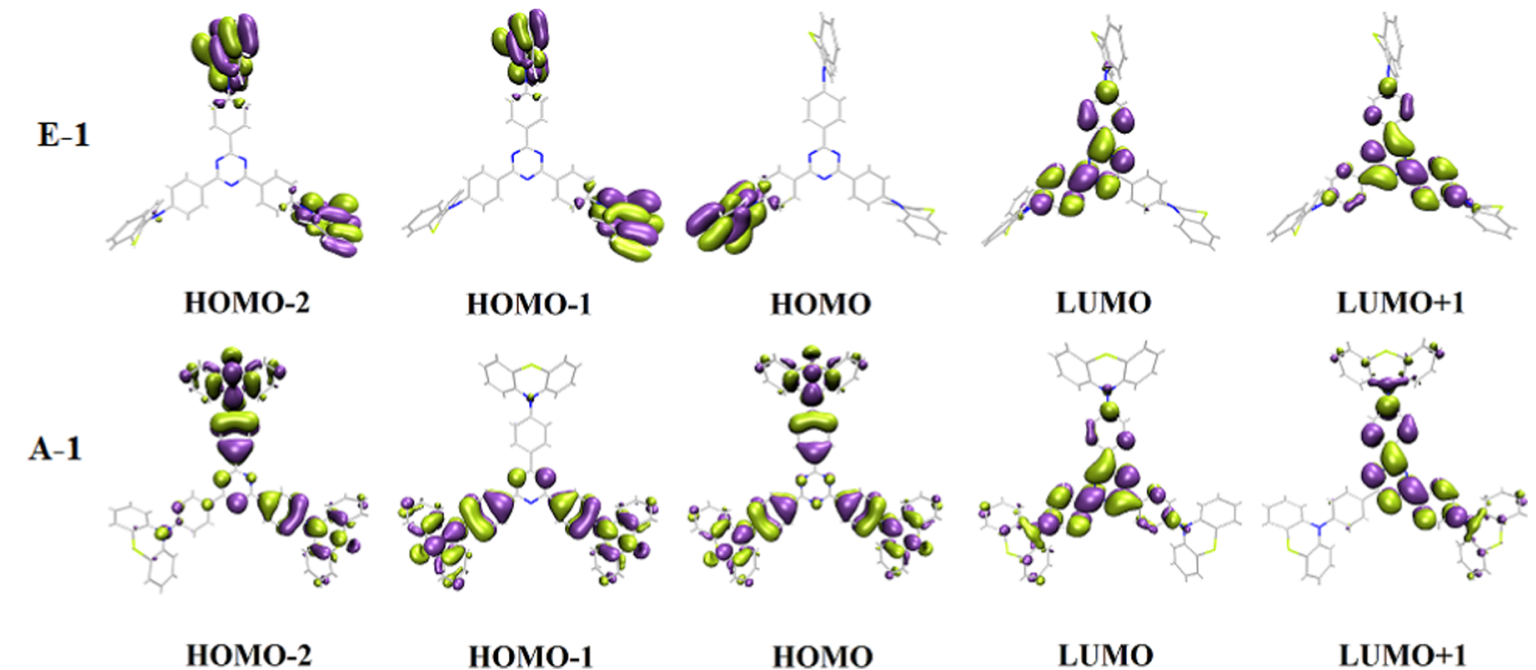

Figure 3. Frontier orbitals of the quasi-equatorial (E-1) and quasi-axial (A-1) conformers, which were calculated at the B3LYP/6-31G* level of theory.

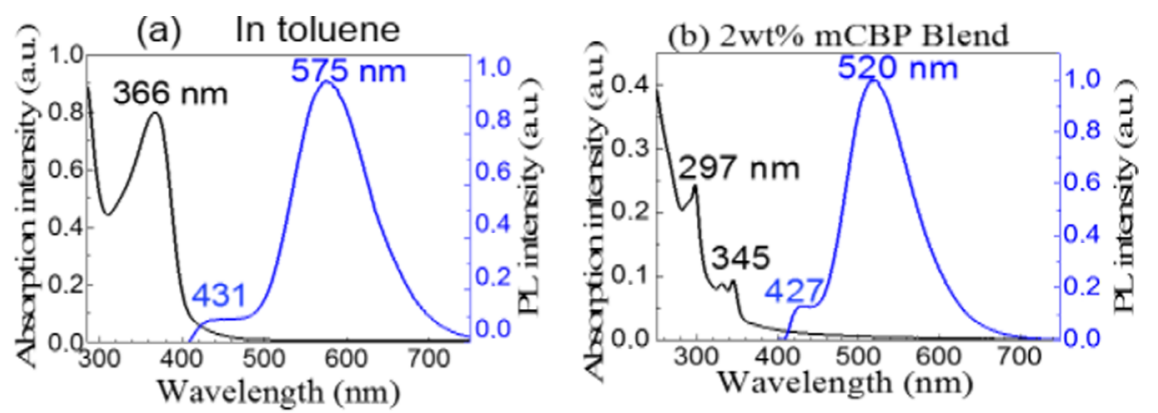

(c) $2 w t \% m C B P$ Blend

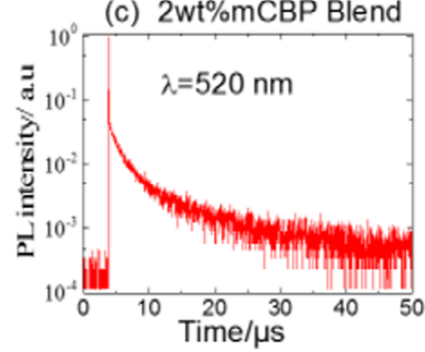

Figure 4. Normalized absorption (black line) and PL (blue line) spectra of TRZ 3(Ph-PTZ) (a) in degassed toluene solution with a concentration of $1 \times 10^{-5} \mathrm{M}$ and (b) in 2 wt \% mCBP blend. PL spectra were obtained using an excitation wavelength of $340 \mathrm{~nm}$. (c) Transient PL decay curve for a 2 wt \% TRZ 3(Ph-PTZ):mCBP film measured at room temperature with an emission wavelength of $520 \mathrm{~nm}$.

polarity of the environments surrounding the TRZ $\mathbf{3}$ (Ph-PTZ) molecules. The transient PL decay of the equatorial conformer in the $\mathrm{mCBP}$ blend was then measured using an excitation wavelength of $337 \mathrm{~nm}$. The PL decay curve displayed in Figure $4 \mathrm{c}$ was fitted by a sum of two exponential decay functions, the fast and slow components corresponding to the prompt and delayed fluorescence, respectively. The prompt and delayed fluorescence lifetimes are measured to be $6.7 \mathrm{~ns}$ and $7.2 \mu \mathrm{s}$, respectively. This result suggests that the highly emissive equatorial conformer of TRZ 3(Ph-PTZ) exhibits a TADF activity, which is consistent with the small $\Delta E_{\mathrm{ST}}$ value obtained by quantum chemistry calculations.

To investigate the electroluminescence properties of TRZ 3(Ph-PTZ), we fabricated OLEDs with the following architecture: indium tin oxide (ITO) $(100 \mathrm{~nm}) / N, N^{\prime}$ diphenyl- $N, N^{\prime}$-bis(1-naphthyl)-1,10-biphenyl-4,4'-diamine $(\alpha$ NPD) $(20 \mathrm{~nm}) /$ tris (4-carbazoyl-9-ylphenyl)amine (TCTA)
$(10 \mathrm{~nm}) / 1,3-$ bis $(N$-carbazolyl)benzene $(\mathrm{mCP})(10 \mathrm{~nm}) / 5 \mathrm{wt}$ $\%$ TRZ 3(Ph-PTZ): m C B P ( $15 \mathrm{~nm}) / \mathrm{bis}[2$ (diphenylphosphino)phenyl] ether oxide (DPEPO) $(10 \mathrm{~nm}) /$ 1,3,5-tris (2-N-phenylbenzimidazolyl)benzene (TPBi) $(55 \mathrm{~nm}) /$ lithium fluoride $(\mathrm{LiF})(0.8 \mathrm{~nm}) /$ aluminum $(\mathrm{Al})(900 \mathrm{~nm})$. A schematic representation of this multilayer structure is provided in Figure 5a, and its energy diagram is shown in Figure S4. In this device, $\alpha$-NPD and mCP are used as hole transport layers, DPEPO as hole blocking layer, and TPBI as electron transport layer. The electroluminescence characteristics of this OLED are displayed in Figure $5 b-d$. The device shows yellowish-green electroluminescence with color coordinates of CIE $(0.23,0.75)$ and exhibits a turn-on voltage of $4.2 \mathrm{~V}$, a maximum current efficiency of $58.6 \mathrm{~cd} / \mathrm{A}$, a power efficiency of $17.4 \mathrm{~lm} / \mathrm{W}$, a maximum luminance up to $7430 \mathrm{~cd} / \mathrm{m}^{2}$, and a high maximum EQE of $17.4 \%$ without any light outcoupling enhancement. As shown in Figure S5, these excellent electroluminescence 


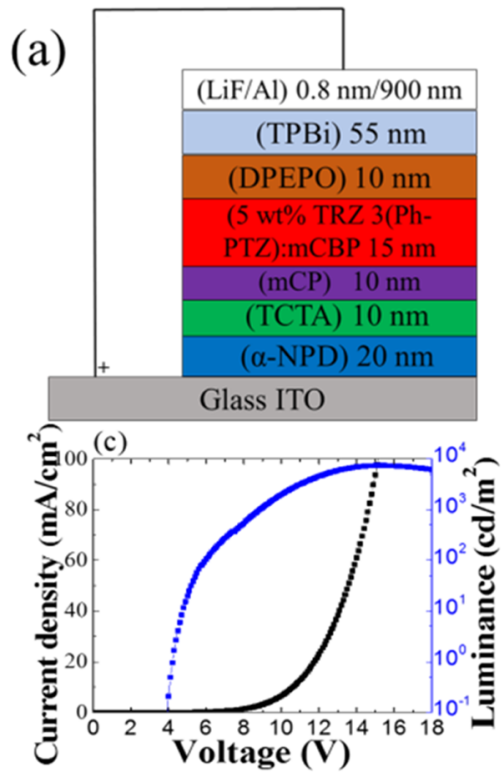

(b)

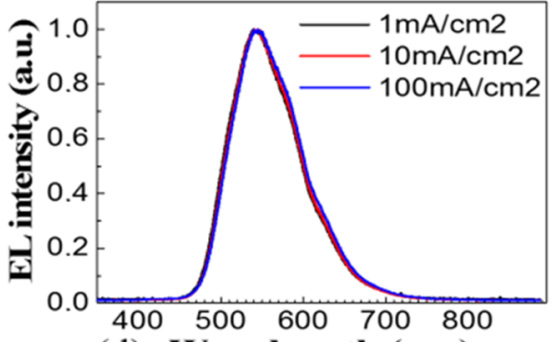

(d) Wavelength (nm)

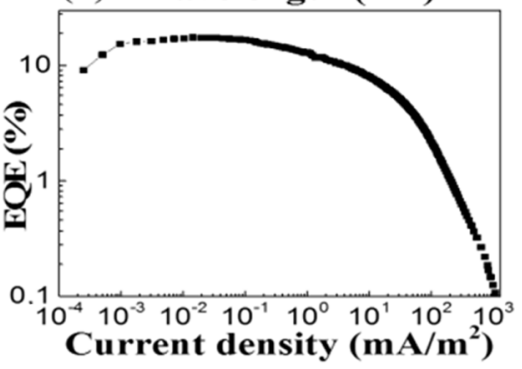

Figure 5. (a) Schematic representation of the OLED structure. (b) Electroluminescence spectra measured at three different current densities. (c) Current density-voltage-luminance characteristic and (d) external quantum efficiency as a function of current density.

performances could be reproduced in several devices. The high EQE value is evidently well beyond the theoretical limit for conventional fluorescent OLEDs and can be attributed to the efficient upconversion of the triplets to singlets through TADF process, which is consistent with the quantum chemistry and PL results presented above. However, it can be seen that the electroluminescence spectra measured in the device for three different current densities do not show any dual emission, in contrast to what was reported in a previous study with a similar emitter. ${ }^{29}$ Further photophysical investigations as well as some device optical and electrical device modeling that are both needed to explain this unexpected result and optimize the dual emission from the devices are now under way. If successful, considering the potential of combining blue and yellow TADF emitters to achieve highly efficient white emission, we believe that TADF emitters with dual emission such as TRZ $\mathbf{3}$ (PhPTZ) should be the subject of more intensive studies in the near future.

\section{CONCLUSIONS}

In summary, the compound TRZ 3(Ph-PTZ) shows excellent TADF characteristics and can be successfully used in a highperformance yellowish-green OLED with a maximum external quantum efficiency of $17.4 \%$. Photophysical measurements demonstrate that this molecule exhibits a dual emission because of the introduction of phenothiazine unit in the molecular structure. This moiety is responsible for the presence of conformers showing different photophysical characteristics. Importantly, the synthesis of this compound is carried out using a simple and convenient method based on cobalt catalyzed cross-coupling. This process can be used to reduce substantially the cost of the synthesis of highly efficient TADF molecules, thanks to the low cost of cobalt employed as catalyst for the synthesis. This advantageous method is used for the first time to synthesize TADF emitters and can easily be extended to other synthetic routes.

\section{EXPERIMENTAL SECTION}

Materials and Methods. All chemicals are reagent/ analytical grade and used without further purification. ${ }^{1} \mathrm{H}$, and ${ }^{13} \mathrm{C}$ NMR spectra were recorded on Brücker AC-300 (300 and $75 \mathrm{MHz}$, respectively) and are internally referenced to residual solvent signals $\left(\mathrm{CDCl}_{3}\right)$. Data for ${ }^{1} \mathrm{H}$ and ${ }^{13} \mathrm{C}$ NMR are reported as follows: chemical shift $(\delta, \mathrm{ppm})$, multiplicity $(\mathrm{s}=$ singlet, $\mathrm{d}=$ doublet, $\mathrm{m}=$ multiplet $)$, coupling constant $(\mathrm{J}$ in $\mathrm{Hz}$ ), integration, and assignment. High-resolution mass spectra were obtained from Ecole Polytechnique Mass Spectral facility. Infrared spectrum was performed with JASCO FT/IR-6100 spectrometer. All of the starting materials were purchased from the usual suppliers (Sigma-Aldrich, Alfa Aesar, and Acros Organics).

Synthesis. 2,4,6-Tris(4-fluorophenyl)-1,3,5-triazine. $\mathrm{CoBr}_{2}$ ( $0.5 \mathrm{mmol}, 109 \mathrm{mg}, 0.1$ equiv) and $\mathrm{Zn}$ dust ( $16.5 \mathrm{mmol}, 1.08 \mathrm{~g}$, 3.3 equiv) were added in $\mathrm{MeCN}(4 \mathrm{~mL})$. The mixture was stirred at room temperature for $1 \mathrm{~h}$ and 4-bromofluorobenzene ( $5 \mathrm{mmol}$ ) was then added. The reaction was stirred to give the (4-fluorophenyl)zinc bromide reagent ( $80 \%$ in GC). 2,4,6Trichloro-1,3,5-triazine (6.5 mmol, 1.3 equiv) was added at room temperature to the unfiltered solution of (4-fluorophenyl)zinc bromide reagent. In the event of a significant rise in temperature, the reaction mixture was cooled with a water bath. The reaction was then stirred for $1 \mathrm{~h}$. The reaction was quenched by addition of saturated aqueous $\mathrm{NH}_{4} \mathrm{Cl}$ solution (20 $\mathrm{mL})$, followed by an extraction with DCM $(3 \times 50 \mathrm{~mL})$. The combined organic layers were dried over $\mathrm{MgSO}_{4}$, and after filtration the solvents were evaporated in vacuum. Purification by flash column chromatography $\left(\mathrm{SiO}_{2}\right.$, petrol ether $/$ EtOAc $=$ $50: 1$ ) afforded the desired product $(908 \mathrm{mg})$ in $50 \%$ overall yield. ${ }^{1} \mathrm{H} \mathrm{NMR}\left(300 \mathrm{MHz}, \mathrm{CDCl}_{3}\right): \delta / \mathrm{ppm}=\delta 8.77(\mathrm{dd}, J=$ 8.7, $5.6 \mathrm{~Hz}, 6 \mathrm{H}), 7.39-7.16(\mathrm{~m}, 6 \mathrm{H}) .{ }^{13} \mathrm{C} \mathrm{NMR}(75 \mathrm{MHz}$, $\left.\mathrm{CDCl}_{3}\right): \delta / \mathrm{ppm}=170.81,169.26,132.30,131.43,115.93 .{ }^{19} \mathrm{~F}$ $\mathrm{NMR}\left(282 \mathrm{MHz}, \mathrm{CDCl}_{3}\right): \delta / \mathrm{ppm}=-106.73$. HRMS $\mathrm{m} / z$ $[\mathrm{M}]^{+}$calcd for $\mathrm{C}_{21} \mathrm{H}_{12} \mathrm{~F}_{3} \mathrm{~N}_{3}, 363.0983$; found, 363.0991.

2,4,6-Tris(4-(10H-phenothiazin-10-yl)phenyl)-1,3,5-triazine (TRZ 3(Ph-PTZ)). An amount of $\mathrm{NaH}(1.14 \mathrm{mmol}, 27 \mathrm{mg}$, 
4 equiv) was washed with $10 \mathrm{~mL}$ of anhydrous pentane for 15 min. To this white product was added and stirred $(0.84 \mathrm{mmol}$, $168 \mathrm{mg}, 3$ equiv) the phenothiazine in $5 \mathrm{~mL}$ of dimethylformamide (DMF). After the liberation of $\mathrm{H}_{2}$ gas had ceased, the orange reaction mixture was stirred for an additional $30 \mathrm{~min}$. Then, $0.28 \mathrm{mmol}$ (101 mg, 1 equiv) of 2,4,6tris(4-fluorophenyl)-1,3,5-triazine in $5 \mathrm{~mL}$ of DMF was added in one batch. The reaction mixture was stirred overnight at 100 ${ }^{\circ} \mathrm{C}$. It was poured into $100 \mathrm{~mL}$ of ice water followed by extraction with DCM $(3 \times 50 \mathrm{~mL})$. The combined organic layers were dried over $\mathrm{MgSO}_{4}$, and the solvents were evaporated in vacuum. Purification by flash column chromatography $\left(\mathrm{SiO}_{2}, \mathrm{CHCl}_{3} /\right.$ cyclohexane $\left.=1: 4\right)$ afforded the desired product $(163.8 \mathrm{mg})$. The yield is more than $65 \% \mathrm{Mp}:>350{ }^{\circ} \mathrm{C}$ (associated with degradation). ${ }^{1} \mathrm{H} \mathrm{NMR}\left(300 \mathrm{MHz}, \mathrm{CDCl}_{3}\right): \delta$ $8.85(\mathrm{~d}, J=8.7 \mathrm{~Hz}, 6 \mathrm{H}), 7.46(\mathrm{~d}, J=8.7 \mathrm{~Hz}, 6 \mathrm{H}), 7.22(\mathrm{~m}, J=$ 7.3, $1.7 \mathrm{~Hz}, 6 \mathrm{H}), 7.03(\mathrm{~m}, J=14.0,7.6,1.6 \mathrm{~Hz}, 12 \mathrm{H}), 6.75(\mathrm{dd}$, $J=8.1,1.4 \mathrm{~Hz}, 6 \mathrm{H}) .{ }^{13} \mathrm{C} \mathrm{NMR}\left(75 \mathrm{MHz}, \mathrm{CDCl}_{3}\right): \delta 171.04$, $146.85,146.76,143.09,133.37,133.20,131.21,127.76,125.79$, $125.24,124.15,123.68,120.39$. IR: $3060,2920,2850,1607$, $1581,1500,1447,1357,1256,1145,1016,922,808,739,616$, $535,476 \mathrm{~cm}^{-1}$. HRMS $\mathrm{m} / z[\mathrm{M}+\mathrm{H}]^{+}$calcd for $\mathrm{C}_{57} \mathrm{H}_{37} \mathrm{~N}_{6} \mathrm{~S}_{3}$, 901.2242; found, 901.2251.

Photophysical Measurements. For the photophysical measurements, the degassed toluene solution of TRZ $3(\mathbf{P h}-$ PTZ) was placed in a quartz cuvette. In parallel, the organic thin film was deposited by thermal evaporation onto a precleaned fused silica substrate. UV-visible absorption and steady-state PL spectra were measured using a UV-2550 spectrometer (Shimadzu) and a Fluoromax-4 spectrophotometer (Horiba Scientific), respectively. The transient PL decay was measured by a streak camera (Hamamatsu Photonics C4334). The samples were placed under vacuum $\left(<4 \times 10^{-1}\right.$ $\mathrm{Pa}$ ) and photoexcited by a nitrogen gas laser (Ken-X, Usho Optical Systems) delivering 500 ps pulses at a repetition rate of $20 \mathrm{~Hz}$ and emitting at $337 \mathrm{~nm}$.

OLED Fabrication and Measurements. The device was prepared using a precleaned indium tin oxide (ITO) substrate. The different organic layers were sequentially thermally evaporated under vacuum lower than $3 \times 10^{-4} \mathrm{~Pa}$. Finally, the $\mathrm{LiF} / \mathrm{Al}$ electrodes were deposited through a shadow mask on top of the multilayer structure. The device active area was 4 $\mathrm{mm}^{2}$. To avoid any degradation and emission quenching due to oxygen and moisture, the OLED was encapsulated in a glovebox filled with nitrogen. The $J-V-L$ characteristics were collected using a source meter (Keithley 2400, Keithley Instruments Inc.) and an absolute external quantum efficiency measurement system (C9920-12, Hamamatsu Photonics). An optical fiber connected to a spectrometer (PMA-12, Hamamatsu Photonics) was used to record the electroluminescence spectrum.

\section{ASSOCIATED CONTENT}

\section{(S Supporting Information}

The Supporting Information is available free of charge on the ACS Publications website at DOI: 10.1021/acsomega.7b01570.

${ }^{1} \mathrm{H} \mathrm{NMR},{ }^{13} \mathrm{C}$ NMR, and ${ }^{19} \mathrm{~F}$ NMR spectra of the 2,4,6tris(4-fluorophenyl)-1,3,5-triazine (2); ${ }^{1} \mathrm{H}$ NMR, ${ }^{13} \mathrm{C}$ NMR, and FTIR spectra of the 2,4,6-tris $(4-(10 H-$ phenothiazin-10-yl)phenyl)-1,3,5-triazine (TRZ 3(PhPTZ)); energy diagram of the fabricated OLEDs; reproducibility of the $\mathrm{EL}$ properties of the TADF
OLEDs; tables summarizing the quantum chemistry calculations (PDF)

\section{AUTHOR INFORMATION}

\section{Corresponding Authors}

*E-mail: ribierre@opera.kyushu-u.ac.jp (J.-C.R.).

*E-mail: adachi@cstf.kyushu-u.ac.jp (C.A.).

ORCID $\odot$

Chihaya Adachi: 0000-0001-6117-9604

Notes

The authors declare no competing financial interest.

\section{ACKNOWLEDGMENTS}

This work was supported by JST ERATO Grant Number JPMJER1305, Japan. We thank Dr. Youichi Tsuchiya for his help with the sublimation and Dr. Sophie Bourcier for the HRMS analysis and fruitful discussion.

\section{REFERENCES}

(1) Tang, C. W.; VanSlyke, S. A. Organic electroluminescent diodes. Appl. Phys. Lett. 1987, 51, 913-915.

(2) Forrest, S. R.; Baldo, M. A.; O’Brien, D. F.; You, Y.; Shoustikov, A.; Sibley, S.; Thompson, M. E. Highly efficient phosphorescent emission from organic electroluminescent devices. Nature 1998, 395, $151-154$.

(3) Kim, K.-H.; Lee, S.; Moon, C.-K.; Kim, S.-Y.; Park, Y.-S.; Lee, J.H.; Woo Lee, J.; Huh, J.; You, Y.; Kim, J.-J. Phosphorescent dye-based supramolecules for high-efficiency organic light-emitting diodes. Nat. Commun. 2014, 5, No. 4769.

(4) Uoyama, H.; Goushi, K.; Shizu, K.; Nomura, H.; Adachi, C. Highly efficient organic light-emitting diodes from delayed fluorescence. Nature 2012, 492, 234-238.

(5) Cui, L. S.; Nomura, H.; Geng, Y.; Kim, J. U.; Nakanotani, H.; Adachi, C. Controlling Singlet-Triplet Energy Splitting for Deep-Blue Thermally Activated Delayed Fluorescence Emitters. Angew. Chem., Int. Ed. 2017, 56, 1571-1575.

(6) Miwa, T.; Kubo, S.; Shizu, K.; Komino, T.; Adachi, C.; Kaji, H. Blue organic light-emitting diodes realizing external quantum efficiency over $25 \%$ using thermally activated delayed fluorescence emitters. Sci. Rep. 2017, 7, No. 284.

(7) Kim, D. H.; Inada, K.; Zhao, L.; Komino, T.; Matsumoto, N.; Ribierre, J. C.; Adachi, C. Organic light-emitting diodes with horizontally oriented thermally activated delayed fluorescence emitters. J. Mater. Chem. C 2017, 5, 1216-1223.

(8) Oh, C. S.; Han, S. H.; Lee, J. Y. Molecular design of thermally activated delayed fluorescent emitters for blue-shifted emission by methoxy substitution. J. Mater. Chem. C 2017, 5, 9106-9114.

(9) Rajamalli, P.; Senthilkumar, N.; Huan, P. Y.; Ren-Wu, C. C.; Lin, H. W.; Cheng, C. H. New molecular design concurrently providing superior pure blue, thermally activated delayed fluorescence and optical out-coupling efficiencies. J. Am. Chem. Soc. 2017, 139, 1094810951.

(10) Kaji, H.; Suzuki, H.; Fukushima, T.; Shizu, K.; Suzuki, K.; Kubo, S.; Komino, T.; Oiwa, H.; Suzuki, F.; Wakamiya, A.; Murata, Y.; Adachi, C. Purely organic electroluminescent material realizing $100 \%$ conversion from electricity to light. Nat. Commun. 2015, 6, No. 8476.

(11) Hirata, S.; Sakai, Y.; Masui, K.; Tanaka, H.; Lee, S. Y.; Nomura, H.; Nakamura, N.; Yasumatsu, M.; Nakanotani, H.; Zhang, Q.; Shizu, K.; Miyazaki, H.; Adachi, C. Highly efficient blue electroluminescence based on thermally activated delayed fluorescence. Nat. Mater. 2015, 14, 330-336.

(12) Zhang, Q.; Kuwabara, H.; Potscavage, W. J.; Huang, S.; Hatae, Y.; Shibata, T.; Adachi, C. Anthraquinone-based intramolecular charge-transfer compounds: computational molecular Design, Thermally Activated Delayed Fluorescence, and highly efficient red electroluminescence. J. Am. Chem. Soc. 2014, 136, 18070-18081. 
(13) Chen, D.; Liu, K.; Gan, L.; Liu, M.; Gao, K.; Xie, G.; Ma, Y.; Cao, Y.; Su, S.-J. Modulation of exciton generation in organic active planar pn heterojunction: Toward low driving voltage and highefficiency OLEDs employing conventional and Thermally Activated Delayed Fluorescent emitters. Adv. Mater. 2016, 28, 6758-6765.

(14) Agrawal, S.; Pastore, M.; Marotta, G.; Reddy, M. A.; Chandrasekharam, M.; De Angelis, F. Optical properties and aggregation of phenothiazine-based dye-sensitizers for solar cells applications: A combined experimental and computational investigation. J. Phys. Chem. C 2013, 117, 9613-9622.

(15) Dance, Z. E. X.; Mi, Q.; McCamant, D. W.; Ahrens, M. J.; Ratner, M. A.; Wasielewski, M. R. Time-Resolved EPR Studies of Photogenerated Radical Ion Pairs Separated by $p$-Phenylene Oligomers and of Triplet States Resulting from Charge Recombination. J. Phys. Chem. B. 2006, 110, 25163-25173.

(16) Kim, S. H.; Kim, H. W.; Sakong, C.; Namgoong, J.; Park, S. W.; Ko, M. J.; Lee, C. H.; Lee, W. I.; Kim, J. P. Effect of five-membered heteroaromatic linkers to the performance of phenothiazine-based dyesensitized solar cells. Org. Lett. 2011, 13, 5784-5787.

(17) Marszalek, M.; Nagane, S.; Ichake, A.; Humphry-Baker, R.; Paul, V.; Zakeeruddin, S. M.; Grätzel, M. Tuning spectral properties of phenothiazine based donor $-\pi$-acceptor dyes for efficient dyesensitized solar cells. J. Mater. Chem. 2012, 22, 889-894.

(18) Meyer, T.; Ogermann, D.; Pankrath, A.; Kleinermanns, K.; Müller, T. J. J. Phenothiazinyl rhodanylidene merocyanines for dyesensitized solar cells. J. Org. Chem. 2012, 77, 3704-3715.

(19) Miura, T.; Carmieli, R.; Wasielewski, M. R. Time-resolved EPR studies of charge recombination and triplet-state formation within donor-bridge-acceptor molecules having wire-like oligofluorene bridges. J. Phys. Chem. A 2010, 114, 5769-5778.

(20) Miura, T.; Wasielewski, M. R. Manipulating photogenerated radical ion pair lifetimes in wirelike molecules using microwave pulses: molecular spintronic gates. J. Am. Chem. Soc. 2011, 133, 2844-2847.

(21) Park, S. S.; Won, Y. S.; Choi, Y. C.; Kim, J. H. Molecular design of organic dyes with double electron acceptor for dye-sensitized solar cell. Energy Fuels 2009, 3732-3736.

(22) Tian, H.; Yang, X.; Chen, R.; Hagfeldt, A.; Sun, L. A metal-free "black dye" for panchromatic dye-sensitized solar cells. Energy Environ. Sci. 2009, 2, 674-677.

(23) Tian, H.; Yang, X.; Chen, R.; Pan, Y.; Li, L.; Hagfeldt, A.; Sun, L. Phenothiazine derivatives for efficient organic dye-sensitized solar cells. Chem. comm. 2007, 36, 3741-3743.

(24) Tsao, M.-H.; Wu, T.-Y.; Wang, H.-P.; Sun, I.-W.; Su, S.-G.; Lin, Y.-C.; Chang, C.-W. An efficient metal-free sensitizer for dye-sensitized solar cells. Mater. Lett. 2011, 65, 583-586.

(25) Wan, Z.; Jia, C.; Duan, Y.; Zhou, L.; Lin, Y.; Shi, Y. Phenothiazine-triphenylamine based organic dyes containing various conjugated linkers for efficient dye-sensitized solar cells. J. Mater. Chem. 2012, 22, 25140-25147.

(26) Xie, Z.; Midya, A.; Loh, K. P.; Adams, S.; Blackwood, D. J.; Wang, J.; Zhang, X.; Chen, Z. Highly efficient dye-sensitized solar cells using phenothiazine derivative organic dyes. Prog. Photovoltaics 2010, $18,573-581$

(27) Tanaka, H.; Shizu, K.; Nakanotani, H.; Adachi, C. Twisted Intramolecular Charge Transfer State for Long-Wavelength Thermally Activated Delayed Fluorescence. Chem. Mater. 2013, 25, 3766-3771.

(28) Wada, Y.; Shizu, K.; Kubo, S.; Suzuki, K.; Tanaka, H.; Adachi, C.; Kaji, H. Highly efficient electroluminescence from a solutionprocessable thermally activated delayed fluorescence emitter. Appl. Phys. Lett. 2015, 107, No. 183303.

(29) Tanaka, H.; Shizu, K.; Nakanotani, H.; Adachi, C. Dual intramolecular charge-transfer fluorescence derived from a phenothiazine-triphenyltriazine derivative. J. Phys. Chem. C 2014, 118, 1598515994.

(30) Tsai, W.-L.; Huang, M.-H.; Lee, W.-K.; Hsu, Y.-J.; Pan, K.-C.; Huang, Y.-H.; Ting, H.-C.; Sarma, M.; Ho, Y.-Y.; Hu, H.-C.; Chen, C.C.; Lee, M.-T.; Wong, K.-T.; Wu, C.-C. A versatile thermally activated delayed fluorescence emitter for both highly efficient doped and non- doped organic light emitting devices. Chem. Comm. 2015, 51, 1366213665.

(31) Kazmierski, I.; Gosmini, C.; Paris, J.-M.; Périchon, J. New progress in the cobalt-catalysed synthesis of aromatic organozinc compounds by reduction of aromatic halides by zinc dust. Tetrahedron Lett. 2003, 44, 6417-6420.

(32) Gosmini, C.; Moncomble, A. Cobalt-Catalyzed Cross-Coupling Reactions of Aryl Halides. Isr. J. Chem. 2010, 50, 568-576.

(33) Gosmini, C.; Amatore, M.; Claudel, S.; Perichon, J. New Efficient Preparation of Functionalized Arylzinc or Thienylzinc Compounds from Aryl or Thienyl Chlorides Using Cobalt Catalysis. Synlett 2005, 2171-2174.

(34) Fillon, H.; Gosmini, C.; Périchon, J. New Chemical Synthesis of Functionalized Arylzinc Compounds from Aromatic or Thienyl Bromides under Mild Conditions Using a Simple Cobalt Catalyst and Zinc Dust. J. Am. Chem. Soc. 2003, 125, 3867-3870.

(35) Fillon, H.; Le Gall, E.; Gosmini, C.; Périchon, J. Pure acetonitrile as solvent for the efficient electrochemical conversion of aryl bromides in organozinc species and their coupling reaction with acetyl chloride. Tetrahedron Lett. 2002, 43, 5941-5944.

(36) Gosmini, C.; Begouin, J.-M.; Moncomble, A. Cobalt-catalyzed cross-coupling reactions. Chem. Commun. 2008, 0, 3221-3233.

(37) Bégouin, J. M.; Claudel, S.; Gosmini, C. Cobalt-Catalyzed Arylation or Benzylation of 2-Chloro-4,6-dimethoxy-1,3,5-triazine. Synlett 2009, 19, 3192-3194.

(38) Marghad, I.; Gosmini, C.; Van der beek, K. Molecules Electroluminescentes Organiques. WO2017125572 A1, 2017.

(39) Marghad, I.; Gosmini, C.; Manolikakes, S. Procede de preparation de molecules electroluminescentes organiques. WO2017125569 A1, 2017.

(40) Biemans, H. A. M.; Zhang, C.; Smith, P.; Kooijman, H.; Smeets, W. J. J.; Spek, A. L.; Meijer, E. W. Hexapyrrolylbenzene and Octapyrrolylnaphthalene. J. Org. Chem. 1996, 61, 9012-9015.

(41) Hrncariková, K.; Szöllosy, Á.; Végh, D. Synthesis and characterization of monofunctionalised hexapyrrolylbenzene derivatives. ARKIVOC 2006, 124-129.

(42) Acar, N.; Kurzawa, J.; Fritz, N.; Stockmann, A.; Roman, C.; Schneider, S.; Clark, T. Phenothiazine-pyrene dyads: photoinduced charge separation and structural relaxation in the CT state. J. Phys. Chem. A 2003, 107, 9530-9541.

(43) Stockmann, A.; Kurzawa, J.; Fritz, N.; Acar, N.; Schneider, S.; Daub, J.; Engl, R.; Clark, T. Conformational control of photoinduced charge separation within phenothiazine-pyrene dyads. J. Phys. Chem. A 2002, 106, 7958-7970. 